\title{
Does osmotic distillation change the isotopic relation of wines?
}

\author{
Matthias Schmitt ${ }^{1, a}$, Marcelo Murgo ${ }^{2, b}$, and Sebastian Prieto $^{2}$ \\ ${ }^{1}$ Hochschule Geisenheim University von Lade Straße 1, 65366 Geisenheim, Germany \\ ${ }^{2}$ Instituto Nacional de Vitivinicultura, Dpto. Estudios Enológicos y Sensoriales San Martín 430 - City, Mendoza
}

\begin{abstract}
Currently partial alcohol reduction of wine is in the focus of research worldwide. There are several technologies available to achieve this target. These techniques are either based on distilling or membrane processes. Osmotic distillation, one of the possibilities, is a quite modern membrane process that can be used. During that process, wine is pumped in counter flow to water along a micro porous, hydrophobic membrane. The volatile components of the wine can permeate that membrane and are dissolved in water. The driving force of that process is the vapor pressure difference between the volatiles on the wine and water side of the membrane. The aim of this work was to determine if the alcohol reduction by osmotic distillation can change the isotopic relation in a wine. Can this enological practice change the composition of a wine in a way that an illegal water addition is simulated? Different wines were reduced by $2 \%$ alcohol v/v with varying process parameters. The isotopic analysis of the O 16/18 ratio in the wine were performed according to the OIV methods (353/2009) These analyses showed that the isotopic ratio is modified by an alcohol reduction of $2 \% \mathrm{v} / \mathrm{v}$ in a way that corresponds to an addition of $4-5 \%$ of external water.
\end{abstract}

\section{Introduction}

Osmotic distillation is a quite new membrane process that is widely used in the beverage industry. It is based on a hydrophobic, micro-porous membrane made out of polyethylene. This membrane can be used in wine industry for gas management. Here you either degas or introduce a selected gas to the wine with that membrane. Another use is the partial alcohol reduction of wine. Here the wine (feed) passes in counter flow to the water (strip) along the membrane. None of the liquids can pass the membrane. The volatiles of the two liquids can pass the membrane by evaporating through its pores. On the other side of the membrane they are then dissolved in the other liquid. Osmotic distillation is an isothermal process at atmospheric pressure. The driving force is the steam pressure difference of a substance between the two sides of the membrane. The volatile components permeate the membrane until an equilibrium arises. The operating pressure is maintained below the capillary penetration pressure of liquids into the pores, the hydrophobic membrane is not wetted by the solutions circulating along the membrane and air gaps are formed into the pores of the membrane [4]. There are several synonyms for the process such as: pervaporation, membrane distillation, trans-membrane distillation or capillary distillation [5].

The alcohol reduction of wine by osmotic distillation has been described by several authors before [4, 6-8, 10$12,14,15,17-19]$.

\footnotetext{
a Matthias.Schmitt@hs-gm.de

${ }^{b}$ marcelo_murgo@inv.gov.ar
}

In general the permeation rate of the volatiles can be influenced by several factors. Besides a higher steam pressure difference, higher temperatures and higher flow speed on both sides of the membrane can accelerate the osmotic distillation [17].

In literature there is some proof that during the alcohol removal there is simultaneous water transfer through the membrane. Some factors can promote the water passage. The higher the operating temperature, the higher the water transfer [17]. If the water is de-gased before the alcohol removal the water transfer is enhanced [3]. When the temperature of the feed is higher than the strip temperature the water also transfers to an higher extend [1].

The amount of water can be up to $3 l / \mathrm{m}^{2} / \mathrm{h}[3,17]$. In case the membrane is leaked due to improper handling the water can flow directly through the membrane.

There are just few information available in what extend the osmotic distillation can change the isotopic relation of a wine, so that an illegal water addition is pretended $[1,2]$.

In this work, wines were treated with different process parameters to evaluate how much this can alter the $\mathrm{O}$ $16 / 18$ ratio. Furthermore, aroma and sensory analysis were conducted.

\section{Material and methods}

The trials were conducted with two commercial Argentinean wines. A white blend with $80 \%$ Sauvignon Blanc 20\% Chardonnay with an alcohol content of 13,6\% $\mathrm{v} / \mathrm{v}$ and a red cuvee with $60 \%$ Malbec and $40 \%$ Sauvignon Blanc that has an alcohol content of $14,0 \% \mathrm{v} / \mathrm{v}$. The trials, chemical and sensorial analyzes were carried out in the

This is an Open Access article distributed under the terms of the Creative Commons Attribution License 4.0, which permits unrestricted use, distribution, and reproduction in any medium, provided the original work is properly cited. 
Chart 1. Characteristics Liqui-Cel ${ }^{\circledR} 2.5 \times 8$ membrane membrane contactor.

\begin{tabular}{|l|l|l|}
\hline Charakteristics & Unity & Membrane fiber X50 \\
\hline Outside diameter & $\mu \mathrm{m}$ & 300 \\
\hline Inner diameter & $\mu \mathrm{m}$ & 200 \\
\hline Bubble pressure & $\mathrm{Bar}$ & 16,5 \\
\hline Breaking load & $\mathrm{g}$ & 430 \\
\hline Porosity & $\%$ & 40 \\
\hline Pore size & $\mu \mathrm{m}$ & 0,03 \\
\hline Flow rate water & $1 / \mathrm{h}$ & $100-700$ \\
\hline Membrane size & $\mathrm{m}^{2}$ & 1,4 \\
\hline
\end{tabular}

Chart 2. Overview of different trial scenarios.

\begin{tabular}{|l|l|l|}
\hline Scenario & $\begin{array}{l}\text { Water/Wine ration } \\
\text { with } \mathbf{1 \%} \text { v/v alcohol } \\
\text { reduction }\end{array}$ & $\begin{array}{l}\text { Operating } \\
\text { temperature }\end{array}$ \\
\hline 1 & $14 \%$ & $20^{\circ} \mathrm{C}$ \\
\hline 2 & $14 \%$ & $40^{\circ} \mathrm{C}$ \\
\hline 3 & $28 \%$ & $40^{\circ} \mathrm{C}$ \\
\hline
\end{tabular}

laboratory of the Instituto National Vitivinicultura (INV) Mendoza/Argentina.

The osmotic distillation conducted with the WineBrane Lab Gas/Alc plant from Inoxpa (Banyoles/Spain). Core part of the plant, the membrane contactor is from Liqui-Cel ${ }^{\circledR}$ (Membrana, Charlote/USA). This membrane contactor was at the time when the trials were conducted 2 years old. The membrane has always been stored and cleaned according to the manufacturer's instructions. An adulteration of the $\mathrm{O} 16 / 18$ isotopic ratio due to a decline in the hydrophobic habit or a leakage of the membrane can be excluded.

The wine (feed) was pumped by a membrane pump (Flojet, St. Ana/USA) with $3001 / \mathrm{h}$ and the water flow (strip) was 1201/h performed by a peristaltic pump (Verder M1500, Haan/Germany).

The trials were carried out with three different scenarios.

The water and the wine were circulated until the alcohol reduction by $2 \% \mathrm{v} / \mathrm{v}$ was reached.

The reagents used are:

Carbon dioxide for analysis:

SMOW (Standard Mean Ocean Water).

GISP (Greenland Ice Sheet Precipitation).

SLAP (Standard Light Arctic Precipitation).

Reference water of own laboratory, carefully contrasted to the reference sample of the International Agency of Atomic Energy in Vienna (IAEA).

Laboratory equipment:

DELTA VTM isotope mass spectrometer with an internal repeatability of $0,05 \%$ (Thermo Fisher, Waltham/USA).

Triple manifold for simultaneous recording of ions $\mathrm{m} / \mathrm{z} 44,45$ and 46 , or alternatively, a double collector for measuring ions $\mathrm{m} / \mathrm{z} 44$ and 46 .

Thermostat controlled system $\left(+0.5^{\circ} \mathrm{C}\right)$ for equilibration between $\mathrm{CO} 2$ and water from wine.

Vacuum pump that can reach an internal pressure of $0.13 \mathrm{~Pa}$.
Sample flasks with a volume of $15 \mathrm{ml}$ and an attached capillary tube having an inner diameter of about $0.015 \mathrm{~mm}$.

Eppendorf pipette with a disposable plastic cone.

The aroma analysis was done in Germany at the Hochschule Geisenheim University by the Institute of microbiology and biochemistry according to Rapp et al. 1994. The method was modified by Fischer and Rauhut as follows:

Modification of the method:

Sample preparation:

$10 \mathrm{~mL}$ wine

$+2 \mathrm{~g} \mathrm{NaCl}$

$+10 \mu \mathrm{L}$ internal standard 2,6-dimethyl-5-hepten-

2-ol (DMH, $1151 \mu \mathrm{g} / \mathrm{L}$ ) for quantification

$+10 \mu \mathrm{L}$ internal standard cumene $(256 \mu \mathrm{g} / \mathrm{L})$ as control

+ $160 \mu \mathrm{L}$ 1,1,2-trichloro-1,2,2-trifluoroethane

20 minutes of shaking by Intelli-Mixer (NeoLab,

Heidelberg/ Germany)

Centrifugation with $3000 \mathrm{rpm}$ for 8 minutes

(Megafuge 1.0, Heraeus Instruments, Hanau/

Germany)

Sampling by glas pipette and drying of the extract by $\mathrm{Na}_{2} \mathrm{SO}_{4}$ (50 mg on mineral wool)

Injection volume $2 \mu \mathrm{L}$

Analytical parameter:

Injection system:

Thermal Desorption Unit KAS 3 (Gerstel, Mülheim an der Ruhr/ Germany)

Splitless mode (1 min)

Start temperature: $30^{\circ} \mathrm{C}$, with $12{ }^{\circ} \mathrm{C} / \mathrm{s}$ until $230^{\circ} \mathrm{C}$, 4 min stay

Gas chromatograph:

GC 5890 Series II, Hewlett Packard

Column: Agilent Varian-5MS: $60 \mathrm{~m} \times 0,32 \mathrm{~mm} \times$

$1 \mu \mathrm{m}$

Carrier gas: helium

solvent vent mode $10 \mathrm{~min}$

Flow: $1,0 \mathrm{~mL} / \mathrm{min}$

Start temperature: $40^{\circ} \mathrm{C}(5 \mathrm{~min})$

With $3{ }^{\circ} \mathrm{C} / \mathrm{min}$ untill $125^{\circ} \mathrm{C}$, with $6^{\circ} \mathrm{C} / \mathrm{min}$ until $200{ }^{\circ} \mathrm{C}(14,2 \mathrm{~min})$

Mass spectrometer:

5972 Mass Selective Detector, Hewlett Packard

Temperature: $180^{\circ} \mathrm{C}$

Mode: Scan (Masse 35 untill 250; 3,43 scans/sec)

The sensory analysis were carried out at the Instituto National Vitivinicultura (INV) Mendoza/Argentina. Several triangle tests were conducted according to ISO 4120:2004 and ISO 8589:1988 (iso.org) to check if there is a significant difference between the the control and the two wines treated in different scenarios (chart 2).

\section{Results and discussion}

The basic wine parameters except of alcohol and sulphur (e.g. total acidity, malic and tartaric acidity, dry extract, volatile acidity and $\mathrm{pH}$ ) are not affected by the alcohol reduction by osmotic distillation $[7,10]$. So it is more 
Chart 3. Change in $\delta \mathrm{O} 18 / \mathrm{O} 16$ due to partial alcohol reduction by osmotic distillation.

\begin{tabular}{|l|c|c|c|}
\hline Test & $\mathbf{\delta} \mathbf{O 1 8} / \mathbf{O 1 6} \%$ & Exogenous water \% & Difference in \% towards initial value \\
\hline White Wine Control & 0,74 & 12 & 0 \\
\hline White Wine Scenario 1 & $-0,15$ & 16 & 5 \\
\hline White Wine Scenario 2 & $-0,24$ & 17 & 5 \\
\hline White Wine Scenario 3 & $-0,30$ & 17 & 0 \\
\hline Red Wine Control & 1,10 & 10 & $5-5$ \\
\hline Red Wine Scenario 1 & $-0,26$ & $14-15$ & 9 \\
\hline Red Wine Scenario 2 & $-0,24$ & 15 & $19-30$ \\
\hline Red Wine Scenario 3 & $-0,69$ & 19 & -19 \\
\hline Red Wine -4,5\% vol. & $-2,89$ & $29-30$ & $-15-16$ \\
\hline Intitial Strip water & $-16,08$ & 93 & -16 \\
\hline $\begin{array}{l}\text { Strip Water White Wine } \\
\text { Scenario 1 }\end{array}$ & $-12,14$ & 74 & -8 \\
\hline $\begin{array}{l}\text { Strip Water White Wine } \\
\text { Scenario 2 }\end{array}$ & $-12,88$ & $77-78$ & -13 \\
\hline $\begin{array}{l}\text { Strip Water White Wine } \\
\text { Scenario 3 }\end{array}$ & $-12,72$ & 77 & -8 \\
\hline $\begin{array}{l}\text { Strip Water Red Wine } \\
\text { Scenario 1 }\end{array}$ & $-14,33$ & 85 & \\
\hline $\begin{array}{l}\text { Strip Water Red Wine } \\
\text { Scenario 2 }\end{array}$ & $-13,38$ & 80 & \\
\hline $\begin{array}{l}\text { Strip Water Red Wine } \\
\text { Scenario 3 }\end{array}$ & $-14,44$ & 85 & \\
\hline
\end{tabular}

Chart 4. Initial content and aroma losses of white wine due due different scenarios of alcohol reduction.

\begin{tabular}{|c|c|c|c|c|c|c|}
\hline & Control & Scenario 1 & Scenario 2 & Scenario 3 & \multicolumn{2}{|c|}{ Outside the calibration } \\
\hline Aroma component & Initial Content & Loss in \% & & & & \\
\hline Ethyl acetate (mg/l) & 50 & $-0,26$ & $-0,43$ & $-0,26$ & $<50 \mathrm{mg} / \mathrm{l}$ & \\
\hline i-Butanol (mg/l) & 18 & $-0,13$ & $-0,13$ & $-0,05$ & $<10 \mathrm{mg} / \mathrm{l}$ & \\
\hline Ethyl propionate $(\mu \mathrm{g} / \mathrm{l})$ & 118 & $-0,22$ & $-0,30$ & $-0,22$ & $<50 \mu \mathrm{g} / \mathrm{l}$ & \\
\hline Isopentyl alcohol (mg/l) & 119 & $-0,16$ & $-0,21$ & $-0,09$ & & \\
\hline 2-methylbutanol (mg/l) & 22 & $-0,16$ & $-0,22$ & $-0,10$ & . & \\
\hline Ethyl butyrate $(\mu \mathrm{g} / \mathrm{l})$ & 345 & $-0,28$ & $-0,34$ & $-0,31$ & & \\
\hline Ethyl L-lactate (mg/l) & 50 & $-0,17$ & $-0,10$ & $-0,03$ & $<25 \mathrm{mg} / \mathrm{l}$ & \\
\hline Hexanol $(\mu \mathrm{g} / \mathrm{l})$ & $n d$ & $n d$ & $n d$ & $n d$ & & \\
\hline Isoamyl acetate $(\mu \mathrm{g} / \mathrm{l})$ & 892 & $-0,86$ & $-0,63$ & $-0,35$ & $<300 \mu \mathrm{g} / \mathrm{l}$ & \\
\hline $\begin{array}{l}\text { 2-Methylbuylacetate } \\
(\mu \mathrm{g} / \mathrm{l})\end{array}$ & 39 & $-0,65$ & $-0,51$ & $-0,25$ & $<25 \mu \mathrm{g} / \mathrm{l}$ & \\
\hline Hexanoic acid (mg/l) & 9 & $-0,07$ & $-0,04$ & $-0,07$ & $>11 \mathrm{mg} / \mathrm{l}$ & \\
\hline Ethyl hexanoate $(\mu \mathrm{g} / \mathrm{l})$ & 429 & $-0,28$ & $-0,31$ & $-0,27$ & & \\
\hline Hexyl acetate $(\mu \mathrm{g} / \mathrm{l})$ & 6 & $n q$ & $n q$ & $n q$ & $<20 \mu \mathrm{g} / \mathrm{l}$ & \\
\hline $\begin{array}{lll}\text { trans } & \text { Linalool } & \text { oxide } \\
(\mu \mathrm{g} / \mathrm{l}) & & \\
\end{array}$ & 50 & 0,04 & 0,02 & $-0,02$ & & \\
\hline Cis Linalool oxide $(\mu \mathrm{g} / \mathrm{l})$ & 22 & 0,11 & 0,08 & 0,06 & $<20 \mu \mathrm{g} / \mathrm{l}$ & \\
\hline Linalool $(\mu \mathrm{g} / \mathrm{l})$ & 51 & $-0,21$ & $-0,18$ & $-0,25$ & $<10 \mu \mathrm{g} / \mathrm{l}$ & \\
\hline $\begin{array}{l}\text { Phenylethyl Alcohol } \\
(\mathrm{mg} / \mathrm{l})\end{array}$ & 15 & 0,02 & 0,05 & 0,11 & & \\
\hline -Octanoic acid (mg/l) & 3 & $-0,05$ & $-0,06$ & $-0,07$ & & \\
\hline Diethyl succinate $(\mu \mathrm{g} / \mathrm{l})$ & 5392 & $-0,11$ & $-0,12$ & $-0,11$ & $<500 \mu \mathrm{g} / \mathrm{l}$ & $>5000 \mu \mathrm{g} / 1$ \\
\hline $\begin{array}{l}\text { Caprylic acid ethyl ester } \\
(\mu \mathrm{g} / \mathrm{l})\end{array}$ & 136 & $-0,40$ & $-0,48$ & $-0,49$ & $<200 \mu \mathrm{g} / \mathrm{l}$ & \\
\hline Alpha-Terpineol $(\mu \mathrm{g} / \mathrm{l})$ & 56 & $-0,06$ & $-0,07$ & $-0,13$ & & \\
\hline $\begin{array}{l}\text { Ethyl phenylacetate } \\
(\mu \mathrm{g} / \mathrm{l})\end{array}$ & 3 & $-0,18$ & 0,07 & 0,20 & $<10 \mu \mathrm{g} / \mathrm{l}$ & \\
\hline Phenethyl acetate $(\mu \mathrm{g} / \mathrm{l})$ & 65 & $-0,80$ & $-0,55$ & $-0,24$ & $<20 \mu \mathrm{g} / \mathrm{l}$ & $>400 \mu \mathrm{g} / \mathrm{l}$ \\
\hline Decanoic acid (mg/l) & 0,2 & $-0,07$ & $-0,13$ & $-0,13$ & $<0.5 \mathrm{mg} / \mathrm{l}$ & \\
\hline Ethyl decanoate $(\mu \mathrm{g} / \mathrm{l})$ & 1,0 & 10,70 & $n q$ & $n q$ & $<50 \mu \mathrm{g} / \mathrm{l}$ & \\
\hline
\end{tabular}


Chart 5. Results triangle test $\mathrm{n}=2 \times 7$.

\begin{tabular}{|c|c|c|c|c|c|}
\hline & $\begin{array}{l}\text { White Wine } \\
\text { Scenario 1 }\end{array}$ & $\begin{array}{l}\text { White Wine } \\
\text { Scenario 2 }\end{array}$ & $\begin{array}{l}\text { White Wine } \\
\text { Scenario 3 }\end{array}$ & $\begin{array}{l}\text { Red Wine } \\
\text { Scenario 3 }\end{array}$ & $\begin{array}{c}\text { Red Wine } \\
\mathbf{- 4 , 5 \%} \text { v/v }\end{array}$ \\
\hline White Wine Control & $\mathrm{ns}$ & - & - & - & - \\
\hline White Wine Control & - & $\mathrm{ns}$ & - & - & - \\
\hline White Wine Control & - & - & $\mathrm{ns}$ & - & - \\
\hline Red Wine Control & - & - & - & $*$ & - \\
\hline Red Wine Control & - & - & - & - & $*$ \\
\hline
\end{tabular}

important to check the volatile components of a wine before and after the treatment.

Chart 3 shows the results of the isotopic analysis of the white wine and the red wine before and after the alcohol reduction by $2 \% \mathrm{v} / \mathrm{v}$, according to the trial scenarios (chart 2 ). Furthermore the isotopic ratio of the strip water before and after the treatments, are shown. Besides the 3 scenarios the red wine, was treated severely so that the alcohol reduction was $4,5 \% \mathrm{v} / \mathrm{v}$.

When comparing the $\delta 018 / 016$ of the wine before and after the treatment, it gets visible that the alcohol reduction by $2 \%$ vol. indicates a water addition to the wine. According to the different scenarios the white wine appears to have 4-5\% external water added. The red wine trials indicate 4-9\% water addition. The most severe change in $\delta \mathrm{O} 18 / \mathrm{O} 16$ gets visible when the alcohol content is reduced by $4,5 \%$ vol.

Contrary to the wine, the strip water shows a lower content of exogenous water after the treatment. This asserts the water transfer from the strip into the feed.

Chart 4 shows the results of the aroma analysis of the white wine. In general the global aroma losses were quite similar for the scenario 1 and 2. The third scenario shows in total slightly lower aroma losses. Most probably this is due to the faster alcohol passage through the membrane, compared to the measured aroma components. This can be explained by ethanol's relatively high steam preassure and the high gradient between feed and strip.

Chart 5 shows the results of the sensory evaluation. There is no significant difference between the white wine control and the different treatments. These results agree with literature $[4,8,16]$

The red wine treated at high temperature and high volumes of strip water shows a significant difference towards the control. This indicates that there is a harming influence of the higher temperature and the high amount of strip water. As expected the alcohol reduction by $4,5 \%$ was significantly different from the control.

\section{Conclusion}

There are several technologies available to reduce the alcohol. There is just a few sources available how the different physical methods can change the integrity of a wine. There is scientific proof that osmotic distillation can change the isotopic relation of a wine [11,12]. This investigation had the aim to check how much osmotic distillation can change the O18/016 isotopic relation. Can this change already pretend an illegal water addition?
Therefore two wines were treated in three different possible scenarios. The scientific theories of literature [3, 17] could be proven. The higher the operating temperature and the higher the volume ratio between feed and strip phase, the higher the water passage through the membrane. According to the process parameters the change in O18/O16 isotopic relation was equal to an addition of 4 $9 \%$ of water.

So far there is no analytical standard for the alcohol reduction by physical methods.

Due to various national restrictions on partial alcohol reduction of wine, there is a need for a reliable proof of the technical intervention to reduce the alcohol content of a wine.

In consequence of various new oenological procedures there is a continuous need to investigate how the integrity of a wine can be influenced.

\section{References}

[1] R. W. Baker., Membrane technology and applications, (2005)

[2] E. Bocca, G. Piubelli, A. Stassi, C. Carbognin \& R. Ferrarini, Effect of dealcoholization through membrane contactor: Composition and evaluation, 33rd World Congress of Vine and Wine, Tbilisi (Georgia), (2010)

[3] P. A., Hogan, R.P., Canning, P.A. Peterson, Johnson, R.A., Michaels, A.S. a new option: osmotic distillation chemical engineering progress, (1998)

[4] N. Diban et al., J. Membr. Sci., 311, (2007)

[5] K. W. Lawson, D.R. Lloyd Membrane distillation. In: J. Membr. Sci. 124, (2005)

[6] L. Liguori, G. Attanasio, D. Albanese, M. Di Matteo Effect of process parameters on partial dealcoholization of wine by osmotic distillation, Food and Bioprocess Technology, (2012)

[7] L. Liguori, G. Attanasio, D. Albanese, M. Di Matteo Aglianico wine dealcoholization tests Computer Aided Chemical Engineering, 28 (C) pp. 325-330, (2010)

[8] M. T Lisanti., A. Gambuti., P. Piombino, R. Pessina, L. Moio Sensory Study on partial dealcoholization of wine by osmotic distillation process, 33th world congress of wine and wine, Tiblis, Georgia, (2010)

[9] Liqui-Cel® product specification sheet, Membrana, Charlotte/USA, (2013) 
[10] S. Motta. Comparison of two techniques for wine dealcoholization, 61. Deutscher Weinbaukongress Stuttgart 23.4, (2013)

[11] R. Ferrarini, G.M. Ciman, L. Cugini, C. Gostoli, M. Simoni, F. Camin, Membrane contactor process to reduce ethanol in wine. Volatilecompounds and stable isotope ratios changes, Alcohol level reduction in wine - Oenoviti international network, Bordeux/France, (2013)

[12] B. Fedrizzi, Nicolis, F. Camin, E. Bocca, C. Carbognin, M. Scholz., P. Barbieri, F. Finato., R. Ferrarini, Stable Isotope Ratios and Aroma Profile Changes Induced, Due to Innovative Wine Dealcoholisation Approaches, Food Bioprocess Technol, February (2013)

[13] A. Rapp, I. Yavas und H. Hastrich: Einfache und schnelle Anreicherung ("Kaltronmethode") von Aromastoffen des Weines und deren quantitative Bestimmung mittels Kapillargaschromatographie, Deutsche Lebensmittelrundschau, 90. Jahrg., Heft 6, S. 171-174, (1994)

[14] O. Schmidt, Alkoholreduzierung mit Membranverfahren - Auf der Suche nach dem Sweet Spot, Rebe und Wein, S.9-13 (2010)
[15] M. Schmitt, Alcohol Management - Reducing the Alcohol Content of Wine Masterthesis Hochschule Rhein Main Fachbereich Geisenheim / Universidade Técnica de Lisboa Instituto Superior de Agronomia, (2010)

[16] Schmitt, M, Christmann, M., Oenological / technical approaches to reduce elevated alcohol levels in wine (alcohol management) - sensory results, 35rd World Congress of Vine and Wine, Bucharest (Rumania/2013)

[17] S. Varavuth, R. Jiraratananon, S. Atchariyawut., Experimental study on dealcoholization of wine by osmotic distillation process, Seperation and Purification Technology, p. 313-321, (2009)

[18] A. Weible, M. Freund, (2011) Reduzierung des Alkohols mittels Membrantechnik, Der Deutsche Weinbau 18, p. 16-18 (2011)

[19] R. Gutte, Prozessbewertung der osmotischen Destillation zur, (2009) Entalkoholisierung von Wein, Dissertation, Institut für Ernährungs- und Lebensmittelwissenschaften, Lehrstuhl für Lebensmitteltechnologie/-biotechnologie, Rheinische FriedrichWilhelms-Universität zu Bonn 